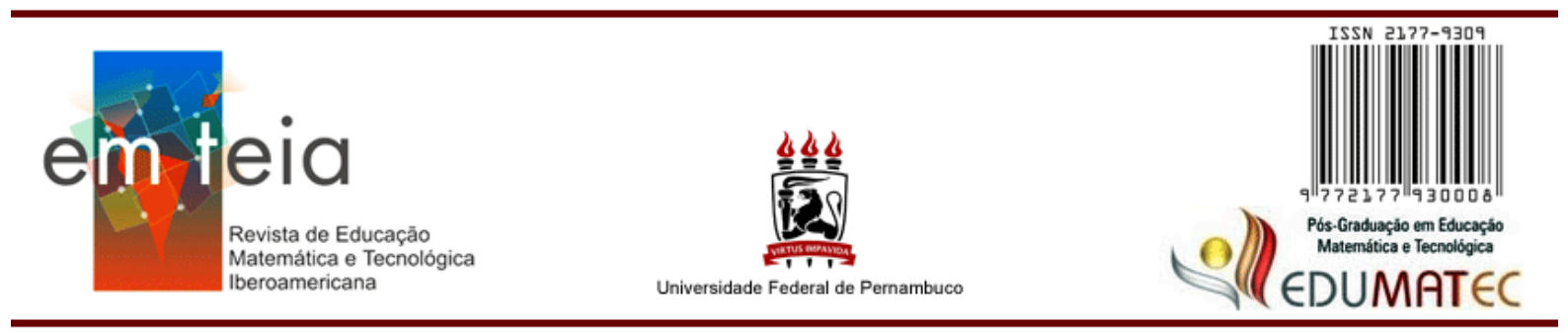

\title{
ENSINO DE ÁLGEBRA NOS ANOS INICIAIS DO ENSINO FUNDAMENTAL:

\author{
uma reflexão sobre a BNCC e o currículo municipal
}

Algebra teaching in the first years of fundamental education:

$A$ reflection on BNCC and the municipal curriculum

\author{
Cintia Aparecida Bento dos Santos \\ Doutora em Ensino de Ciências e Matemática \\ Universidade Cruzeiro do Sul - SP - Brasil \\ Cintia.santos@cruzeirodosul.edu.br \\ Eder Anelli da Silva \\ Mestrando em Ensino de Ciências \\ Universidade Cruzeiro do Sul - SP - Brasil \\ Prof.ederanelli@gmail.com
}

\section{Resumo}

Este artigo tem por objetivo realizar uma reflexão de como é proposto o pensamento algébrico nos anos iniciais do Ensino Fundamental ( $1^{\circ}$ a $5^{\circ}$ ano), com base na BNCC (2017) e no Currículo da cidade de São Paulo (2019), considerando seu Ciclo de Alfabetização ( $1^{\circ}$ ao $3^{\circ}$ ano) e Ciclo Interdisciplinar (apenas $4^{\circ}$ e $5^{\circ}$ ano), a fim de verificar a consonância de ambos os documentos. Para atender nosso objetivo de investigação realizamos uma pesquisa qualitativa de natureza documental e trazemos também a perspectiva de autores que discutem o ensino de álgebra em sua linguagem, pensamento próprio e específico, que desenvolve capacidades matemáticas e conhecimentos algébricos que permitem ao aluno contextualizar e ampliar seus processos cotidianos, nas mais abrangentes situações. Ao final constatamos que apesar da consonância dos documentos analisados em relação ao proposto para o ensino de álgebra nesta etapa de escolarização, há necessidade de evolução do material, no que tange à formação continuada do professor que trabalhará esse conteúdo em sala e que esta reflexão pode ampliar estudos futuros sobre esta temática.

Palavras-Chave: BNCC. currículo municipal. Álgebra. Pensamento algébrico. Anos iniciais.

\begin{abstract}
This article aims to reflect on how algebraic thinking is proposed in the early years of elementary school (1st to 5th year), based on the BNCC (2017) and the curriculum of the city of São Paulo (2019), considering its cycle Literacy (1st to 3rd year) and Interdisciplinary Cycle (only 4th and 5th year), in order to verify the consonance of both documents. To meet our research objective, we carried out a qualitative research of a documentary nature and also bring the perspective of authors who discuss the teaching of algebra in their language, their own and specific thinking, which develops
\end{abstract}


mathematical skills and algebraic knowledge that allow students to contextualize and expand their knowledge. everyday processes, in the most comprehensive situations. At the end we found that despite the consonance of the analyzed documents in relation to the proposed one for the teaching of algebra in this stage of schooling, there is a need for evolution of the material, regarding the continued education of the teacher who will work this content in class and that this reflection can expand future studies on this topic.

Keywords: BNCC. Municipal curriculum. Algebra. Algebraic thinking. early years.

\section{Introdução}

A álgebra é indispensável para o entendimento de mundo do indivíduo no contexto em que está inserido. Assim, diversos são os autores que discutem e corroboram meios e ações para a inserção da álgebra nos diversos níveis de ensino, de modo a proporcionar ao aluno a aquisição de competências e habilidades, além de auxiliar na construção de seu papel na sociedade.

Mesmo que reconhecida por muitos em caráter tradicional, ou seja, por meio de cálculos e uso de simbologias, suas discussões promovem uma linguagem variada e própria que permite ao pensamento algébrico construir-se, em seus diversos aspectos, com a evolução dos ciclos de ensino do discente. E qual o objetivo da álgebra? Por muito tempo foi reduzida a cálculos expressivos e meras equações, mas com a evolução de seu pensamento mostrou-se eficaz sob a ótica de uma construção contextualizada e que demonstre sentido ao aluno, faça parte de seu cotidiano e possa compreender desde situações generalizadas de simples operações matemáticas, permitindo, nesse formato, sua aplicação aos anos iniciais do Ensino Fundamental, contemplando os ciclos de alfabetização $\left(1^{\circ}\right.$ ao $3^{\circ}$ ano $)$ e o ciclo interdisciplinar $\left(4^{\circ}\right.$ e $5^{\circ}$ ano $)$

Com a atenção voltada para as relações existentes entre os objetos matemáticos, o pensamento algébrico permite a representação e o raciocínio de modo geral e abstrato, sendo necessário considerar sua não redução a simbolismos, mas sim a uma abrangente diversidade de situações, que envolvam relações, variações, modelos e regularidades. Iniciar o pensamento algébrico não é reproduzir conceitos, mas conceber novas perspectivas do ensino da Álgebra, desenvolvendo capacidades matemáticas e construção de conhecimentos algébricos ao aluno, de modo a compreender e ampliar seus processos matemáticos (CANAVARRO, 2007).

Discutiremos durante o texto a construção inovadora do pensamento algébrico, pela Base Nacional Comum Curricular (BNCC) nos anos iniciais do Ensino Fundamental $\left(1^{\circ}\right.$ ao 5 
ano), documento base oficial do Brasil vigente desde 2017, com foco na ampliação pelo Currículo da cidade de São Paulo, desenvolvido pela Secretaria Municipal da Educação no ano de 2019, baseando-se nessa mesma faixa de ensino, em que se utiliza a nomenclatura de Ciclo de Alfabetização ( $1^{\circ}$ ao $3^{\circ}$ ano) e Ciclo Interdisciplinar, contemplando neste, apenas o $4^{\mathrm{o}}$ e $5^{\mathrm{o}}$ ano.

A reflexão aqui apresentada tem por objetivo discutir em específico como se apresenta o pensamento algébrico, com base nos documentos curriculares mencionados anteriormente nesta fase de escolarização dos Ciclos de Alfabetização e Interdisciplinar. Para esta abordagem foi utilizada uma metodologia qualitativa com base no método de análise documental, que conforme Caulley (1981) identifica informações nos documentos, por meio de questões ou hipóteses de interesse.

Assim, partiremos das principais ideias do ensino da álgebra nos anos iniciais do Ensino Fundamental, indicando a perspectiva de autores sobre a introdução da álgebra e suas características em função do pensamento do aluno. Em seguida, apresentaremos o documento da BNCC em relação às suas orientações para o desenvolvimento e a construção do pensamento algébrico, desde a introdução do pensamento até as propostas de objetos de conhecimentos e habilidades que os alunos devem obter ao longo dos 5 anos que compõem essa fase do Ensino Fundamental.

Por fim, será apresentada uma reflexão sobre o Currículo da cidade de São Paulo, desde as suas concepções iniciais sobre o ensino da álgebra nessa fase inicial do Ensino Fundamental, passando pelos objetos de conhecimento e objetivos de aprendizagem a serem obtidos durante os anos de estudo do Ensino Fundamental ( $1^{\circ}$ ao $5^{\circ}$ ano).

Para essa leitura, é importante atentar para a relação existente entre os documentos e a convergência entre os objetivos a serem obtidos em sala de aula, de modo a se tornar eficaz o ensino da álgebra nos anos iniciais do Ensino Fundamental.

\section{O Ensino da Álgebra}

Para fomentar a discussão sobre ensino da álgebra no currículo, é preciso levarmos em consideração a perspectiva de alguns autores sobre os conteúdos algébricos.

Assim, consideremos os Ciclos de Alfabetização e Interdisciplinar como o período de construção do pensamento algébrico, que iniciam os trabalhos investigativos do uso dos números e operações que vão se aperfeiçoando no decorrer dos anos de escolarização, ou seja, nas etapas seguintes. Blanton e Kaput (2005) caracterizam esse pensamento por um processo 
generalizado pelos alunos, que em meio a discursos argumentativos desenvolvem expressões que progridem de maneira adequada à sua idade.

É importante ressaltar que a álgebra não se resume na utilização de símbolos em seus cálculos ou descobertas "mirabolantes", mas durante seu processo constrói uma linguagem própria e natural, traduzindo sua forma de pensamento e representações diversificadas. Canavarro (2007) reflete que por meio desses símbolos expressa uma forma única e importante de comunicação e ideais, que resultam no raciocínio algébrico utilizado para compreensão.

Segundo Usiskin (1995), a primeira concepção da Álgebra é a Aritmética Generalizada. É nessa linha de pensamento que introduzimos as primeiras ideias algébricas para os anos iniciais do Ensino Fundamental. Pensando em cálculos simples e inversos que induzem ao pensamento algébrico, os alunos dos ciclos da alfabetização e interdisciplinar praticam cálculos naturais, muitas vezes voltados para conceitos de seu cotidiano ou que lidam, com frequência, com o desenvolvimento de suas atividades.

Para Usiskin (1995), o pensamento algébrico pode ser iniciado nos ciclos iniciais do Ensino Fundamental com a manipulação de adições, produtos e potências de números, referindo-se à generalização da aritmética. Assim, como exemplo, essa ação está relacionada à compreensão de cálculos inversos da adição, por exemplo, em que aprendem que $4+3=7$ e que 3+4 também é igual a 7, mesmo com a ordem estrutural alterada, que em uma concepção algébrica mais avançada e que atinge outros níveis de ensino, esta operação seria representada pela expressão que $a+b=b+a$.

Mesmo parecendo simples, a tarefa de ensinar álgebra não é a das mais fáceis, visto que é um processo matemático que exige muito do aluno, mesmo nos níveis iniciais, pois se deve levar em consideração a faixa de idade em que se encontra o educando, além do nível de aprendizado adquirido até o momento. Ponte, Branco e Matos (2008) salientam que o raciocínio em álgebra requer a compreensão da linguagem algébrica, sendo por isso de grande importância compreender a natureza e origem das dificuldades dos estudantes.

É importante observar que os anos iniciais abrangem duas etapas de vivência do aluno, nas quais no ciclo de alfabetização, a álgebra está voltada para o desenvolvimento de raciocínios e representações (como indicar o número que falta para completar a sequência numérica, por exemplo), de modo que a comunicação do aluno não fique prejudicada e os conceitos matemáticos sejam trabalhados de forma situacional e que associem sentido ao aluno. Já nos anos em que a "primeira" etapa do ensino fundamental se encerra ( $4^{\circ}$ e $5^{\circ}$ ano), 
deve-se ampliar os conhecimentos algébricos do aluno (como o cálculo de "números desconhecidos", por exemplo), promovendo sua autonomia e desenvolvendo análises e formulações de hipóteses, além da criação de uma linguagem própria e que permita o letramento matemático ao educando.

Nessa perspectiva, a matemática deverá estar relacionada à compreensão e apreensão de significados, considerando suas aplicações e significados, de modo a conectar os alunos ao estudo do componente e de ações do cotidiano (BNCC, 2017). Assim, utilizar os recursos tecnológicos matemáticos poderá auxiliar no processo de construção do pensamento algébrico, como vídeos, jogos, softwares educativos, calculadoras, entre outros, a fim de desenvolver a reflexão do aluno, mediante sistemas e procedimentos formais a serem realizados.

Propostas curriculares já aderem ao uso desses recursos, como o Currículo da Cidade de São Paulo, em que as tecnologias são enfatizadas em todos os ciclos de aprendizagem. No Ciclo de Alfabetização ( $1^{\circ}$ ao $3^{\circ}$ ano) esses recursos estarão direcionados a leituras e situações numéricas, além de outras não especificadas; já no Ciclo Interdisciplinar (considerando apenas o $4^{\circ}$ e $5^{\circ}$ ano), o uso dos recursos digitais estará voltado para o reconhecimento de figuras, desenhos etc. Veremos mais a fundo as propostas da álgebra do currículo da cidade, em tópico posterior.

Na sequência, seguem exemplos de exercícios destinados ao eixo de Álgebra, em que identificamos a evolução do pensamento algébrico e que podem ser trabalhados ao longo dos anos iniciais do Ensino Fundamental.

Figura 1 - Exercício: $1^{\mathrm{o}}$ ano

4. COMPLETE O QUADRO, ESCREVENDO OS NÚMEROS QUE FORAM COBERTOS POR CARTÕES COLORIDOS.

\begin{tabular}{|c|c|c|c|c|c|c|c|c|c|}
\hline 0 & & 2 & 3 & 4 & 5 & & 7 & 8 & 9 \\
\hline 10 & 11 & 12 & & 14 & 15 & 16 & 17 & 18 & 19 \\
\hline & 21 & 22 & 23 & 24 & & 26 & 27 & 28 & \\
\hline
\end{tabular}

Fonte: Caderno Trilhas de Aprendizagem (2020, p. 53).

A figura 1 é um exemplo de exercício pertinente ao $1^{\circ}$ ano, no qual percebemos que os alunos deverão indicar os números que faltam (desconhecidos), a partir da contagem dos números sequenciais, em ordem crescente. 
Figura 2 - Exercício: $2^{\circ}$ ano

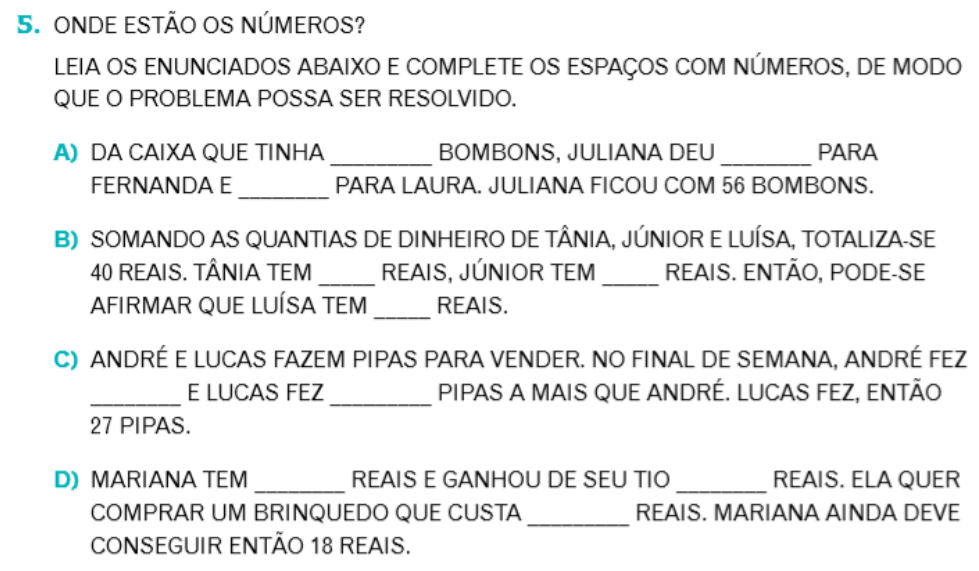

Fonte: Caderno Trilhas de Aprendizagem (2020, p. 62)

No exercício apresentado para o $2^{\circ}$ ano na figura 2 , podemos verificar que neste os alunos deverão indicar as quantidades (desconhecidas) de cada elemento, a partir do total já indicado no exercício, veja que em uma visão ampla, trabalham-se conceitos de uma variável.

Figura 3 - Exercício: $3^{\circ}$ ano

B) DESCUBRA OS SEGREDOS DA FORMAÇÃO DAS SEQUÊNCIAS ABAIXO E EM SEGUIDA, COMPLETE OS NÚMEROS QUE ESTÃO FALTANDO:

\begin{tabular}{|c|c|c|c|c|c|c|c|}
\hline 10 & & 30 & 50 & 70 & & & 100 \\
\hline 110 & & & 150 & & 180 & & \\
\hline & 171 & & & & & 178 & \\
\hline
\end{tabular}

Fonte: Caderno Trilhas de Aprendizagem (2020, p. 64)

Com esse exercício da figura 3, prescrito para o $3^{\circ}$ ano, o aluno deverá indicar os números que faltam na sequência (desconhecidos), a partir da observação da contagem progressiva dos números, ideia intrínseca ao resolver este problema. 
Figura 4 - Exercício: $4^{\mathrm{o}}$ ano

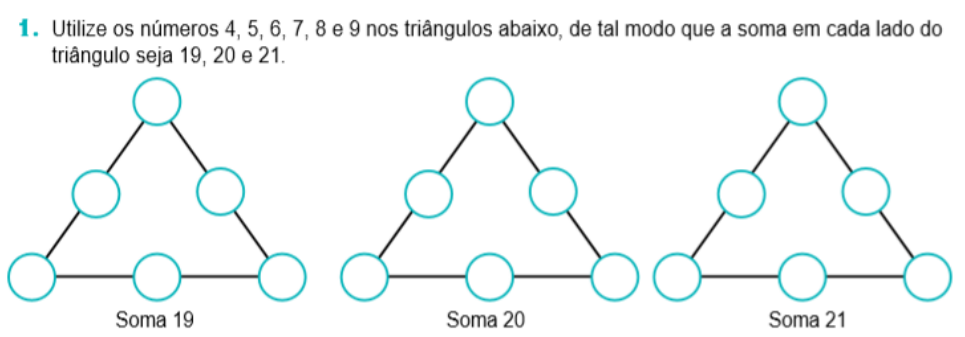

Fonte: Caderno Trilhas de Aprendizagem (2020, p. 61)

Destinado ao $4^{\circ}$ ano, a figura 4 evidencia um modelo de exercício que permite ao aluno desenvolver a ideia da igualdade, onde observando a posição dos números, deverá obter o resultado indicado para cada triângulo expresso.

Figura 5 - Exercício: $5^{\circ}$ ano

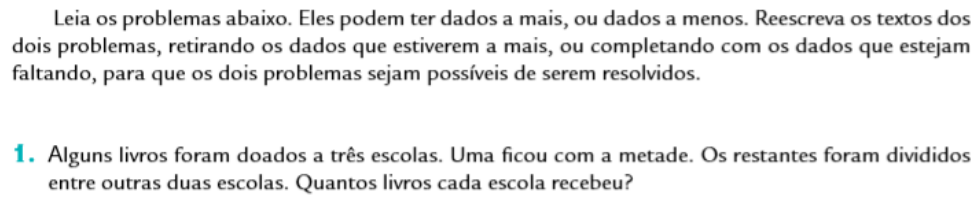

Fonte: Caderno Trilhas de Aprendizagem (2020, p. 65)

Já a figura 5 apresenta um modelo de situação-problema mais elaborada; o aluno do $5^{\circ}$ ano deverá observar o problema e indicar valores que o construam de tal forma que a ideia de proporcionalidade esteja expressa e seja verdadeira.

\section{A Álgebra proposta na BNCC}

A Base Nacional Comum Curricular (BNCC) é um documento de caráter normativo, vigente desde 2017 que define as aprendizagens essenciais que todos os alunos devem desenvolver nas etapas e modalidades da Educação Básica, assegurando seus direitos de aprendizagem e desenvolvimento (BRASIL, 2017). Essas aprendizagens são identificadas pelas competências que mobilizam os conhecimentos, habilidades, atitudes e valores, a fim de resolver complexidades cotidianas, da cidadania e do mundo do trabalho (BRASIL, 2017).

Retomando o foco dos estudos da Álgebra, a BNCC inova ao inserir essa temática desde os anos iniciais do Ensino Fundamental, pois acredita ser imprescindível que suas dimensões estejam presentes nessa etapa de escolarização, com ideais generalizados e reguladores de padrões e propriedades. Assim, sendo a álgebra uma das temáticas propostas 
pela Base, ela reforça seu "tipo especial de pensamento", pois é utilizada para compreensão, representação e análises de grandezas matemáticas, utilizando letras e símbolos. Mas, quando falado nos anos iniciais, a BNCC (BRASIL, 2017, p. 270) deixa claro que "[...] nessa fase, não se propõe o uso de letras para expressar regularidades, por mais simples que sejam".

Nesse sentido, observamos que suas ideias conversam com a proposta de Usiskin (1995), pois, de maneira generalizada, a álgebra será trabalhada nos anos iniciais do Ensino Fundamental, introduzindo seu pensamento de forma contextualizada e envolvendo o cotidiano do aluno, por meio de cálculos simples e não estruturais, no sentido de que o aluno identificará ausências numéricas, por exemplo, analisando o uso dos próprios números, sem simbologias ou métodos alternativos. Assim, é evidente a criação de uma linguagem própria, pois o aluno será protagonista dessa construção e o professor mediador, ação essa evidente pela BNCC, quando reforça que o pensamento algébrico não se resumirá a símbolos e procedimentos técnicos, mas a uma linguagem desenvolvida para o ensino da álgebra, que nesse nível de ensino, terá um trabalho relacional muito grande com os números.

Apresentamos as indicações para os anos iniciais do Ensino Fundamental $\left(1^{\circ}\right.$ ao $5^{\circ}$ ano), quanto ao ensino da álgebra, sendo uma fase importante e intuitiva, pois seu aprendizado, que neste momento será específico e introdutório, proporcionará condições para os mais complexos que serão desenvolvidos em etapas futuras. Esse pensamento deixa claro o exemplo mencionado anteriormente, em que ao aprender que $4+3=3+4$, conceitos básicos de funções já são observados, mas não com essa nomenclatura.

No quadro 1 são apresentados os respectivos objetos de conhecimento propostos para álgebra, a cada ano e suas respectivas habilidades.

Quadro 1 - Objetos de conhecimento e habilidades para álgebra na BNCC

\begin{tabular}{|c|c|c|}
\hline Ano & Objetos de conhecimento & Habilidades \\
\hline \multirow[b]{2}{*}{$1^{\circ}$} & $\begin{array}{l}\text { Padrões figurais e numéricos: } \\
\text { investigação de regularidades } \\
\text { ou padrões em sequências }\end{array}$ & $\begin{array}{l}\text { (EF01MA09) Organizar e ordenar objetos familiares ou } \\
\text { representações por figuras, por meio de atributos, tais } \\
\text { como cor, forma e medida. }\end{array}$ \\
\hline & 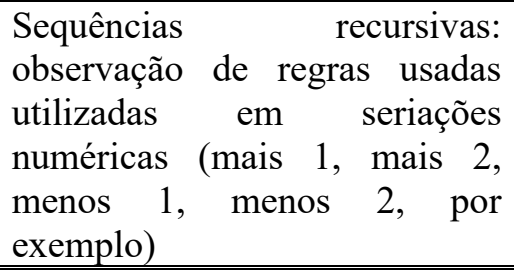 & $\begin{array}{l}\text { (EF01MA10) Descrever, após o reconhecimento e a } \\
\text { explicitação de um padrão (ou regularidade), os } \\
\text { elementos ausentes em sequências recursivas de } \\
\text { números naturais, objetos ou figuras. }\end{array}$ \\
\hline & 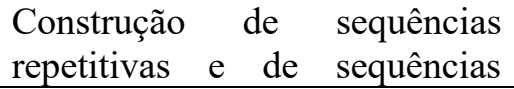 & $\begin{array}{l}\text { (EF02MA09) Construir sequências de números naturais } \\
\text { em ordem crescente ou decrescente a partir de um }\end{array}$ \\
\hline
\end{tabular}




\begin{tabular}{|c|c|c|}
\hline \multirow{2}{*}{$2^{\circ}$} & recursivas & $\begin{array}{l}\text { número qualquer, utilizando uma regularidade } \\
\text { estabelecida. }\end{array}$ \\
\hline & $\begin{array}{l}\text { Identificação de } \text { regularidade } \\
\text { de sequências e determinação } \\
\text { de elementos } \\
\text { sequência }\end{array}$ & $\begin{array}{l}\text { (EF02MA10) Descrever um padrão (ou regularidade) de } \\
\text { sequências repetitivas e de sequências recursivas, por } \\
\text { meio de palavras, símbolos ou desenhos. } \\
\text { (EF02MA11) Descrever os elementos ausentes em } \\
\text { sequências repetitivas e em sequências recursivas de } \\
\text { números naturais, objetos ou figuras. }\end{array}$ \\
\hline \multirow[t]{2}{*}{$3^{\circ}$} & $\begin{array}{l}\text { Identificação e descrição de } \\
\text { regularidades em sequências } \\
\text { numéricas recursivas }\end{array}$ & $\begin{array}{l}\text { (EF03MA10) Identificar regularidades em sequências } \\
\text { ordenadas de números naturais, resultantes da realização } \\
\text { de adições ou subtrações sucessivas, por um mesmo } \\
\text { número, descrever uma regra de formação da sequência } \\
\text { e determinar elementos faltantes ou seguintes. }\end{array}$ \\
\hline & Relação de igualdade & $\begin{array}{l}\text { (EF03MA11) Compreender a ideia de igualdade para } \\
\text { escrever diferentes sentenças de adições ou de } \\
\text { subtrações de dois números naturais que resultem na } \\
\text { mesma soma ou diferença. }\end{array}$ \\
\hline \multirow{4}{*}{$4^{\circ}$} & $\begin{array}{l}\text { Sequência numérica recursiva } \\
\text { formada por múltiplos de um } \\
\text { número natural }\end{array}$ & $\begin{array}{l}\text { (EF04MA11) Identificar regularidades em sequências } \\
\text { numéricas compostas por múltiplos de um número } \\
\text { natural. }\end{array}$ \\
\hline & $\begin{array}{l}\text { Sequência numérica recursiva } \\
\text { formada por números que } \\
\text { deixam o mesmo resto ao } \\
\text { serem divididos por um mesmo } \\
\text { número natural diferente de } \\
\text { zero }\end{array}$ & $\begin{array}{l}\text { (EF04MA12) Reconhecer, por meio de investigações, } \\
\text { que há grupos de números naturais para os quais as } \\
\text { divisões por um determinado número resultam em restos } \\
\text { iguais, identificando regularidades. }\end{array}$ \\
\hline & $\begin{array}{l}\text { Relações entre adição e } \\
\text { subtração e entre multiplicação } \\
\text { e divisão }\end{array}$ & $\begin{array}{l}\text { (EF04MA13) Reconhecer, por meio de investigações, } \\
\text { utilizando a calculadora quando necessário, as relações } \\
\text { inversas entre as operações de adição e de subtração e } \\
\text { de multiplicação e de divisão, para aplicá-las na } \\
\text { resolução de problemas. }\end{array}$ \\
\hline & Propriedades da igualdade & $\begin{array}{l}\text { (EF04MA14) Reconhecer e mostrar, por meio de } \\
\text { exemplos, que a relação de igualdade existente entre } \\
\text { dois termos permanece quando se adiciona ou se subtrai } \\
\text { um mesmo número a cada um desses termos. } \\
\text { (EF04MA15) Determinar o número desconhecido que } \\
\text { torna verdadeira uma igualdade que envolve as } \\
\text { operações fundamentais com números naturais. }\end{array}$ \\
\hline \multirow[t]{2}{*}{$5^{\circ}$} & $\begin{array}{l}\text { Propriedades da igualdade e } \\
\text { noção de equivalência }\end{array}$ & $\begin{array}{l}\text { (EF05MA10) Concluir, por meio de investigações, que } \\
\text { a relação de igualdade existente entre dois membros } \\
\text { permanece ao adicionar, subtrair, multiplicar ou dividir } \\
\text { cada um desses membros por um mesmo número, para } \\
\text { construir a noção de equivalência. } \\
\text { (EF05MA11) Resolver e elaborar problemas cuja } \\
\text { conversão em sentença matemática seja uma igualdade } \\
\text { com uma operação em que um dos termos é } \\
\text { desconhecido. }\end{array}$ \\
\hline & $\begin{array}{l}\text { Grandezas } \\
\text { proporcionais }\end{array}$ & $\begin{array}{l}\text { (EF05MA12) Resolver problemas que envolvam } \\
\text { variação de proporcionalidade direta entre duas } \\
\text { grandezas, para associar a quantidade de um produto ao } \\
\text { valor a pagar, alterar as quantidades de ingredientes de }\end{array}$ \\
\hline
\end{tabular}




\begin{tabular}{|l|l|l|}
\hline $\begin{array}{l}\text { Problemas envolvendo a a } \\
\text { partição de um todo em duas } \\
\text { partes proporcionais }\end{array}$ & $\begin{array}{l}\text { receitas, ampliar ou reduzir escala em mapas, entre } \\
\text { outros. } \\
\text { (EF05MA13) Resolver problemas envolvendo a partilha } \\
\text { de uma quantidade em duas partes desiguais, tais como } \\
\text { dividir uma quantidade em duas partes, de modo que } \\
\text { uma seja o dobro da outra, com compreensão da ideia de } \\
\text { razão entre as partes e delas com o todo. }\end{array}$ \\
\hline
\end{tabular}

Fonte: Adaptado pelos autores com base na BNCC (BRASIL, 2017, p. 278-297.

Por meio dos objetos de conhecimento e habilidades propostas para o ensino de álgebra, nos anos iniciais do Ensino Fundamental, é possível observar que o desenvolvimento do pensamento algébrico parte de uma álgebra generalizada, que proporcionará caminhos para que seja aprofundada nas etapas seguintes a esse nível. É importante salientar a não utilização de simbologias e métodos complexos nessa fase, visto seu objetivo ser a alfabetização e o letramento matemático.

Vale ressaltar que o ensino de álgebra neste nível de ensino trabalhará em conjunto com os demais eixos, pois tem por objetivo a alfabetização do aluno em um longo processo contextualizado, até que o letramento seja consolidado e de competência do aluno. A própria BNCC, nessa perspectiva, indica competências específicas a serem atingidas no decorrer do ensino aprendizado do aluno, dentro dos anos iniciais.

Segundo a BNCC (BRASIL, 2017, p. 267):

Compreender as relações entre conceitos e procedimentos dos diferentes campos da Matemática (Aritmética, Álgebra, Geometria, Estatística e Probabilidade) e de outras áreas do conhecimento, sentindo segurança quanto à própria capacidade de construir e aplicar conhecimentos matemáticos, desenvolvendo a autoestima e a perseverança na busca de soluções.

A citação se refere à terceira competência elencada pelo documento em seu quadro de Competências Específicas de Matemática para o Ensino Fundamental, ela se refere à importância da relação entre os diferentes campos como um trabalho integrado. Assim, corrobora a ideia dos autores mencionados, visto que o ensino generalizado da álgebra, durante os anos iniciais, utilizará de recursos de outros eixos para introduzir o pensamento algébrico, de modo abstrato, porém fundamentado e base para evolução posterior.

É importante lembrar que por estarmos tratando de um nível de ensino em que o aluno precisa começar a construir a autonomia de seu aprendizado, principalmente no contexto da álgebra, por utilizar recursos dos cotidianos e experiências do próprio aluno para alfabetizá-lo nesse eixo, a BNCC (2017, p. 267) propõe: 
Desenvolver e/ou discutir projetos que abordem, sobretudo, questões de urgência social, com base em princípios éticos, democráticos, sustentáveis e solidários, valorizando a diversidade de opiniões de indivíduos e de grupos sociais, sem preconceitos de qualquer natureza.

Assim, evidenciar nas aulas assuntos que os alunos trazem ou dialogam entre si e que podem ser ferramentas para o ensino da álgebra se torna um fator positivo e agregador de valores, pois facilitará o desenvolvimento do pensamento algébrico do aluno, além de compreender seu papel perante a sociedade e sua inserção no meio, pois em um mundo tecnológico em que hoje vivemos e que atinge todas as fases do desenvolvimento humano, sendo de fácil acesso e linguagem adaptada ao usuário, o estudo da álgebra poderá auxiliar no desenvolvimento do pensamento computacional, permitindo ao aluno traduzir situações de outras linguagens para sua língua materna, compreendendo fórmulas, gráficos e outros itens, de maneira geral, mas com a necessidade dessa base de pensamento (BRASIL, 2017).

Essas ideias estão de acordo com Ursini et al. (2005, p. 23), ao dizer que "Integrar os diferentes usos para vê-los como aspectos distintos de um mesmo objeto matemático, que se revelam dependendo da situação particular", pois estas são as dificuldades encontradas por estudantes nos níveis avançados do estudo da álgebra, que trazem essa deficiência já do ensino básico, por não terem claros os conteúdos propostos nos anos iniciais. Isso reforça a importância da inserção do pensamento algébrico desde o início do ensino fundamental, que por meio da alfabetização ( $1^{\circ}$ ao $3^{\circ}$ ano $)$ e do letramento $\left(4^{\circ}\right.$ e $5^{\circ}$ ano $)$ o aluno terá condições de realizar ações cotidianas necessárias, além do uso das tecnologias, seja por questões pessoais ou de uso escolar.

\section{Análise do ensino de álgebra no currículo da cidade de São Paulo}

Vigente a partir de 2017, o currículo da cidade de São Paulo foi elaborado pensando na vivência e no cotidiano dos alunos, contemplando no processo de ensino da matemática diferentes estratégias em acordo com questões atuais e relevantes aos estudantes, atendendo sua realidade e tornando-se compatível com sua aprendizagem e atribuição de significados que contribuam para seu ensino (SÃO PAULO, 2017). Alinhada à Base Nacional Comum Curricular (BNCC), tem como propósito central orientar o trabalho escolar, com especificidade na sala de aula, sendo parte de um processo transformador e qualificador, a partir das práticas adotadas. 
Separado por eixos, o documento no que se refere ao componente curricular da Matemática está estruturado em cinco tópicos (Números, Álgebra, Geometria, Grandezas e Medidas, Probabilidade e Estatística), chamados de "eixos estruturantes" e articulado por outros três (jogos e brincadeiras, conexões extra matemática e processos matemáticos), chamados de "eixos articuladores". Esses eixos estão inseridos no currículo que está subdividido em três ciclos, que coincidem com o tempo de desenvolvimento do aluno em suas fases da vida: Ciclo de Alfabetização, período de construção contínua do saber, que abrange do $1^{\circ}$ ao $3^{\circ}$ ano; Ciclo Interdisciplinar, do $4^{\circ}$ ao $6^{\circ}$ ano, que integra saberes básicos e permite diálogos entre as diferentes áreas e; o Ciclo Autoral, que permite a ampliação dos saberes e a compreensão da realidade, no período do $7^{\circ}$ ao $9^{\circ}$ ano.

Com um ato inovador, a BNCC inclui a álgebra como um dos eixos estruturantes do componente curricular Matemática, estando assim o currículo da cidade em conformidade com sua base.

A diferença está na nomenclatura, pois o currículo da cidade de São Paulo está dividido em ciclos, abrangendo o de Alfabetização e o Interdisciplinar, que na BNCC é chamado de Anos Iniciais do Ensino Fundamental, excluindo apenas o $6^{\circ}$ ano que faz parte de outra etapa, não correlacionada entre os dois documentos.

No quadro 2 são apresentados para álgebra seus objetos de conhecimento e seus respectivos objetivos de aprendizagem e desenvolvimento.

Quadro 2 - Objetos de conhecimentos e objetivos de aprendizagem e desenvolvimento para álgebra no currículo da cidade de São Paulo

\begin{tabular}{|c|c|c|}
\hline Ano & Objetos de conhecimento & Objetivos de aprendizagem e desenvolvimento \\
\hline \multirow[b]{2}{*}{$1^{\circ}$} & \multirow{2}{*}{$\begin{array}{l}\text { - Padrões numéricos ou figurais } \\
\text { - Regras de formação de uma } \\
\text { sequência numérica ou figural }\end{array}$} & $\begin{array}{l}\text { (EF01M14) Organizar e ordenar objetos } \\
\text { familiares ou representações figurais por meio } \\
\text { de atributos, tais como cor, formato e medida. }\end{array}$ \\
\hline & & $\begin{array}{l}\text { (EF01M15) Investigar e descrever oralmente } \\
\text { um padrão (ou uma regularidade) e identificar } \\
\text { elementos ausentes em sequências recursivas } 7 \\
\text { numéricas ou figurais }\end{array}$ \\
\hline \multirow{3}{*}{$2^{\circ}$} & \multirow{3}{*}{$\begin{array}{l}\text { - Sequências repetitivas e sequências } \\
\text { recursivas: construção, identificação, } \\
\text { descrição de padrões e regularidades e } \\
\text { determinação de elementos ausentes. }\end{array}$} & $\begin{array}{l}\text { EF02M13) Construir sequências de números } \\
\text { naturais, em ordem crescente ou decrescente, a } \\
\text { partir de um número qualquer, utilizando uma } \\
\text { regularidade estabelecida. }\end{array}$ \\
\hline & & $\begin{array}{l}\text { (EF02M14) Descrever oralmente um padrão } \\
\text { (ou regularidade) de sequências numéricas ou } \\
\text { figurais, repetitivas ou recursivas } 9 \text {, por meio de } \\
\text { palavras ou de representações pessoais. }\end{array}$ \\
\hline & & $\begin{array}{l}\text { (EF02M15) Descrever elementos ausentes em } \\
\text { sequências numéricas ou figurais, repetitivas ou }\end{array}$ \\
\hline
\end{tabular}




\begin{tabular}{|c|c|c|}
\hline & & $\begin{array}{l}\text { recursivas, por meio de palavras ou de } \\
\text { representações pessoais e continuar a sequência } \\
\text { a partir de um padrão. }\end{array}$ \\
\hline \multirow{3}{*}{$3^{\circ}$} & \multirow{3}{*}{$\begin{array}{l}\text { - Identificação e } \\
\begin{array}{l}\text { regularidades } \\
\text { numéricas }\end{array} \\
\text { - Relação de igualdade em diferentes } \\
\text { sequências } \\
\text { sentenças matemáticas envolvendo } \\
\text { adições ou subtrações }\end{array}$} & $\begin{array}{l}\text { (EF03M12) Investigar } \text { regularidades em } \\
\text { sequências ordenadas de números naturais, } \\
\text { resultantes da realização de adições ou de } \\
\text { subtraç̃es sucessivas de um mesmo número. }\end{array}$ \\
\hline & & $\begin{array}{l}\text { (EF03M13) Descrever um padrão (ou } \\
\text { regularidade) de uma sequência numérica ou } \\
\text { figural recursiva e determinar elementos } \\
\text { faltantes ou seguintes. }\end{array}$ \\
\hline & & $\begin{array}{l}\text { (EF03M14) Compreender a ideia de igualdade } \\
\text { para escrever diferentes sentenças de adições } \\
\text { ou de subtrações de dois números naturais que } \\
\text { resultem na mesma soma ou diferença }\end{array}$ \\
\hline \multirow[b]{2}{*}{$4^{\circ}$} & \multirow{2}{*}{$\begin{array}{l}\text { - Sequência numérica recursiva } \\
\text { formada por múltiplos de um número } \\
\text { natural } \\
\text { - Propriedades da igualdade }\end{array}$} & $\begin{array}{l}\text { (EF04M15) Explorar regularidades, em } \\
\text { sequências numéricas recursivas, compostas } \\
\text { por múltiplos de um número natural. }\end{array}$ \\
\hline & & $\begin{array}{l}\text { (EF04M16) Investigar o número desconhecido } \\
\text { que torna verdadeira uma igualdade que } \\
\text { envolve as operações fundamentais com } \\
\text { números naturais. }\end{array}$ \\
\hline \multirow{3}{*}{$5^{\circ}$} & \multirow[t]{3}{*}{ - Propriedades da igualdade } & $\begin{array}{l}\text { (EF05M11) Investigar que uma igualdade não } \\
\text { se altera ao adicionar ou subtrair, multiplicar ou } \\
\text { dividir os seus termos por um mesmo número. }\end{array}$ \\
\hline & & $\begin{array}{l}\text { (EF05M12) Solucionar problemas que } \\
\text { envolvam ampliação ou redução de quantidades } \\
\text { de forma proporcional. }\end{array}$ \\
\hline & & $\begin{array}{l}\text { (EF05M13) Solucionar problemas envolvendo } \\
\text { a partilha de uma quantidade em duas partes } \\
\text { desiguais, tais como dividir uma quantidade em } \\
\text { duas partes, de modo que uma seja o dobro da } \\
\text { outra. }\end{array}$ \\
\hline
\end{tabular}

Fonte: Adaptado pelos autores com base no Currículo da cidade de São Paulo, p. 85-105

No quadro 2 é possível identificar a adequação do pensamento algébrico, conforme os anos de escolarização se passam. Os objetos de conhecimento e objetivos de aprendizagem são apresentados em um formato generalizado, com um pensamento introdutório e abstrato que vai ganhando uma linguagem própria, concreta, mais complexa e adequada aos alunos com o avanço de seus respectivos níveis de ensino.

Retomando a tratativa dos Ciclos que norteiam os Anos Iniciais do Ensino Fundamental, o Ciclo da Alfabetização leva em consideração as experiências vivenciadas pela criança, além de seu desenvolvimento e participação social, no que se refere ao ensino de matemática. É uma fase que se preocupa com a leitura e escrita do aluno, que também passará por um processo de alfabetização matemática. Nesse contexto, e observando os objetivos de aprendizagem do $1^{\circ}$ ao $3^{\circ}$ ano, etapas que compõem esse ciclo, percebemos que seu 
desenvolvimento estará aplicado a situações contextualizadas e que permitirão ao aluno alfabetizar-se, compreender a leitura e o pensamento algébrico, relacionar àquilo que está vivendo no seu dia a dia, pois, para Stacey (1989, p. 147), “Tais relações permitem que as crianças estabeleçam generalizações próximas, quando a questão formulada pode ser resolvida passo a passo por contagem ou desenho".

Para contextualizar, utilizamos o objeto de conhecimento "Padrões numéricos ou figurais" que tem por objetivo de aprendizagem e desenvolvimento "Organizar e ordenar objetos familiares ou representações figurais por meio de atributos, tais como cor, formato e medida", correspondente ao $1^{\circ}$ ano do Ensino Fundamental, no eixo da álgebra. Os conteúdos abordados nessa fase de ensino deverão levar em consideração que os alunos acabaram de sair da Educação Infantil, obtêm conhecimentos lúdicos acerca dos assuntos, porém seus conceitos ainda não estão concretizados para o uso cotidiano, sendo necessária a alfabetização matemática.

$\mathrm{Na}$ figura 6 apresentamos um exemplo prático presente no caderno Trilhas de Aprendizagem (2020, p. 54 - 55), que faz parte dos materiais desenvolvidos pela Secretaria Municipal da Educação e que contempla o currículo da cidade de São Paulo, e atende ao objetivo de aprendizagem mencionado.
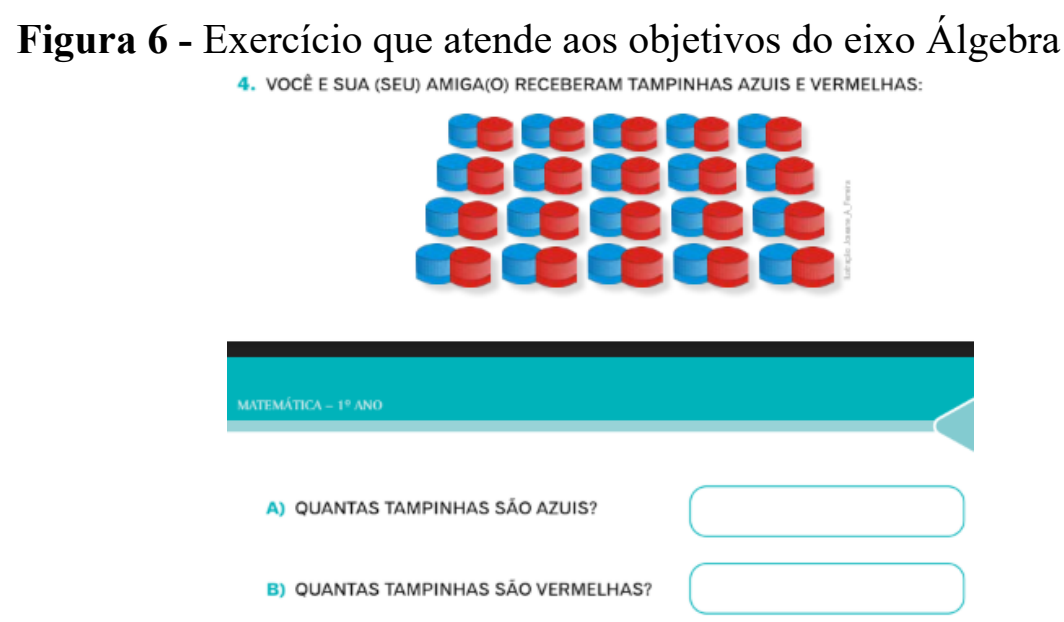

Fonte: Caderno Trilhas de Aprendizagem

Nesse exercício, identificamos que para resolução o aluno deverá realizar, além de uma simples contagem, uma organização, por cores, a fim de conseguir indicar quantas são as tampinhas azuis e vermelhas apresentadas na figura, sendo necessária uma leitura específica daquilo que está observando. É importante ressaltar que a compreensão do aluno estará voltada para o lúdico (desenhos iguais que permitem o entendimento do aluno, para saber que 
todos são uma "tampinha” e a diferenciação estará no contexto das cores) e, esses dois itens juntos constroem a alfabetização matemática do aluno, em que ele não mais olhará e dirá que o desenho tem "tampinhas azul ou vermelha" ou simplesmente pegar uma a uma delas, dizendo "uma azul" e "uma vermelha" para todas, mas saberá que a leitura dessa imagem e resolução do exercício se transformarão em uma linguagem própria e operação matemática da adição intrínseca, de que existem 20 tampinhas azuis e 20 tampinhas vermelhas, totalizando 40 tampinhas.

Vale ressaltar que essa linha de pensamento vai evoluindo com o avançar dos níveis de ensino do aluno. Nessa perspectiva, observamos o Ciclo Interdisciplinar considerando apenas o $4^{\circ}$ e $5^{\circ}$ ano que compõem os anos iniciais do Ensino Fundamental. Fase essa que descrevem os processos matemáticos e os relacionam à língua materna do aluno, passando de um processo de alfabetização para o letramento matemático. Para Carpenter et al. (2005, p. 53), "O pensamento relacional, a construção de generalizações ocorre a partir de relações numéricas e das operações aritméticas e suas propriedades, e ainda da noção de equivalência associada ao sinal de igual (=)".

Observando o eixo temático da Álgebra no $4^{\circ}$ ano, com o objeto de conhecimento "Propriedade da igualdade" e objetivo de aprendizagem "Investigar o número desconhecido que toma verdadeira uma igualdade que envolve as operações fundamentais com números naturais", analisaremos a questão da figura 7, proposta no Caderno Trilhas de Aprendizagens (2020, p. 86):

Figura 7 - Atividade proposta considerando eixo da Álgebra - $4^{\circ}$ ano

1. Agora, é com vocel! Arrume os dominós numéricos de modo que a soma dos números dos quadradinhos de qualquer fileira (horizontal ou vertical) seja a mesma:

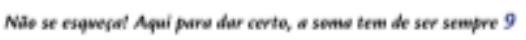
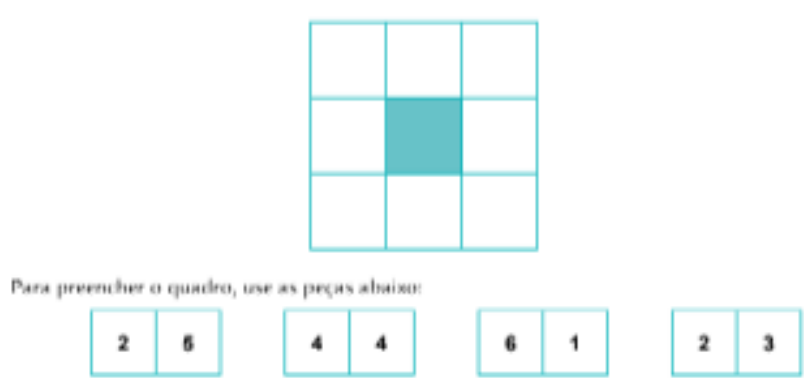

Fonte: Caderno Trilhas de Aprendizagens

Para resolução desse exercício (figura 7), o aluno já precisa de um domínio maior do sistema de numeração, ou seja, já terá construído com mais ênfase o letramento matemático, saindo da alfabetização e partindo para a aplicação conceitual sobre o exercício. Mesmo que o 
resultado que deverá ser obtido já é indicado, no caso o 9 , o aluno deverá posicionar corretamente as peças de dominó, de modo a obter esse resultado. Logo, por meio de propriedades de igualdade e com a disposição ainda desconhecida, o educando irá raciocinar sobre a disposição das peças, tomando por verdadeira a "sentença" do resultado.

Assim, ao compararmos os exercícios propostos nos diferentes ciclos, percebemos a evolução do pensamento algébrico dentro dos anos iniciais do ensino fundamental, que inicia com conceitos básicos e contextualizados, que vão agregando valores no decorrer das etapas, permitindo ao aluno a alfabetização e o letramento, além da percepção e prática de inserção da álgebra em seu cotidiano.

\section{Considerações finais}

Considerando os documentos apresentados, percebemos que há consonância entre o currículo da cidade de São Paulo e a BNCC, em que ambos inserem o ensino da álgebra por meio de pensamentos específicos, desde os anos iniciais do Ensino Fundamental.

A BNCC, como ato inovador, considera o eixo da álgebra caminhos para a construção de um pensamento contextualizado e acessível ao aluno, permitindo a obtenção de conceitos que serão mais elaborados no decorrer dos anos de estudo, ou seja, conforme a evolução das etapas de ensino, pensamento este que também está presente no Currículo da cidade, porém levando consigo o fato da adaptação regional em que está inserida, produzindo conceitos claros e que façam parte daquilo que realmente os alunos vivem, por meio de exemplos, exercícios contextualizados, práticas promissoras, entre outros, além de considerar as fases da vida do aluno, permitindo que seu crescimento como ser humano faça parte de seu processo de construção como cidadão, permitindo alfabetizar-se e letrar-se por meio do ensino da Matemática.

Os autores que discutem o assunto e apresentam concepções consideráveis acerca do ensino da álgebra relacionam-se veemente com a proposta do currículo municipal e da BNCC, mostrando que, por meio de apresentações generalizadas e expressivas, os alunos poderão desenvolver a base daquilo que será trabalhado, mais especificadamente, em níveis e ciclos posteriores.

Ressalta-se que nos anos iniciais do Ensino Fundamental, os eixos matemáticos acabam por atuarem em conjunto, visto a generalização do assunto e, por muitas vezes, passa desapercebida ao olhar do professor a análise de como poderá ser inserido ou estar sendo utilizado o pensamento algébrico em suas aulas. Falamos de docentes que não possuem 
formação específica em matemática, mas que utilizam da condução do currículo para introduzir esse pensamento aos alunos.

É válido, em pesquisas futuras, relacionar os documentos analisados nesse artigo com os materiais destinados aos professores e alunos, como os cadernos do professor e aluno do próprio município de São Paulo, a fim de avaliar como efetivamente se dá a estrutura proposta pelo currículo, nos conteúdos desenvolvidos ao discente em sala de aula, observando questões do tipo: o currículo acontece na região determinada? Os conteúdos estão adequados aos níveis de ensino propostos? É possível atender aos objetivos do currículo, com o material proposto? Entre outras questões que podem ser de valia para o processo de ensino e aprendizagem de álgebra.

Como evolução do material, vislumbramos a necessidade de uma formação continuada aos professores que atuam do $1^{\mathrm{o}}$ ao $5^{\mathrm{o}}$ ano, em ensino matemático, para que compreendam, de fato, as orientações mediadas no currículo da cidade de São Paulo e propostas apresentadas pela BNCC, visto que, por muitas das vezes, a linguagem elaborada por especialistas da área matemática pode dificultar o entendimento desses professores pedagogos que estarão em contato direto com o material e trabalhando com eles junto aos alunos no dia a dia, uma vez que no decorrer de seu ciclo de formação, podem não ter obtido o conhecimento básico necessário para o eficaz desenvolvimento do pensamento algébrico nessa fase de ensino.

Diante do exposto, fica evidente a necessidade do ensino da álgebra desde o $1^{\mathrm{o}}$ ano do Ensino Fundamental, pois, por meio desse processo de alfabetização e letramento, será possível ao aluno autonomia no seu conhecimento sobre a temática, por etapas e de modo contextualizado, a fim de o assunto fazer sentido para si, no processo de construção de seu papel como cidadão e também como estudante, ao longo das etapas de ensino abrangidas.

\section{Referências}

BLANTON, M.; KAPUT, J. Characterizing a classroom practice that promotes algebraic reasoning. Journal for Research in Mathematics Education, v. 36, n. 5, p. 412-446, 2005.

BRASIL. Base Nacional Comum Curricular. Brasília, 2017. Disponível em: $<$ http://basenacionalcomum.mec.gov.br/wp-content/uploads/2018/02/bncc-20dezsite.pdf $>$ Acesso em: 5 mar. 2020. 
CANAVARRO, A. P. O pensamento algébrico na aprendizagem da Matemática nos primeiros anos. Quadrante, Lisboa, v. 16, n. 2, p. 81-118, 2007.

CARPENTER et al. Algebra in the elementary school: Developing relational thinking. ZDM: The International Journal on Mathematics Education, Springer Berlin Heidelberg, v. 37, n. 1, p. 53-59, 2005.

CAULlEY, D. N. Document Analysis in program Evaluation. Or. Northwest Regional Educacional laboratory (n. 60 na série paper and Report Series of the Research on Evaluation Program). Portland, 1981.

PONTE, J. P.; BRANCO, N.; MATOS, A. O simbolismo e o desenvolvimento do pensamento algébrico dos alunos. Revista Educação e Matemática, Lisboa, n. 100, p. 89-96, nov./dez. 2008.

SÃO PAULO (SP). Secretaria Municipal de Educação. Coordenadoria Pedagógica. Currículo da Cidade: Ensino Fundamental: Matemática. São Paulo: SME/COPED, 2017.

SÃO PAULO (SP). Secretaria Municipal de Educação. Coordenadoria Pedagógica. Trilhas de aprendizagens: Ensino Fundamental $-1^{\circ}$ ano. São Paulo: SME/COPED, 2020 .

SÃO PAULO (SP). Secretaria Municipal de Educação. Coordenadoria Pedagógica. Trilhas de aprendizagens: Ensino Fundamental $-2^{\circ}$ ano. São Paulo: SME/COPED, 2020 .

SÃO PAULO (SP). Secretaria Municipal de Educação. Coordenadoria Pedagógica. Trilhas de aprendizagens: Ensino Fundamental $-3^{\circ}$ ano. São Paulo: SME/COPED, 2020 .

SÃO PAULO (SP). Secretaria Municipal de Educação. Coordenadoria Pedagógica. Trilhas de aprendizagens: Ensino Fundamental $-4^{\circ}$ ano. São Paulo: SME/COPED, 2020 .

SÃO PAULO (SP). Secretaria Municipal de Educação. Coordenadoria Pedagógica. Trilhas de aprendizagens: Ensino Fundamental $-5^{\circ}$ ano. São Paulo: SME/COPED, 2020 .

STACEY, K. Finding and using patterns in linear generalising problems. Educational Studies in Mathematics, v. 20, n. 2, p. 147-164, 1989.

URSINI, S.; ESCARENO, F.; MONTES, D.; TRIGUEIROS, M. Ensenanza del álgebra elemental: uma propuesta alternativa. Mexico: Trillas, 2005. 
USISKIN, Z. Concepções sobre a álgebra da escola média e utilizações das variáveis. In: COXFORD, Arthur F.; SHULTE, Alberto P. (Org.). As ideias da álgebra. São Paulo: Atual, 1995. 